Gut, 1961, 2, 44

\title{
Palliative surgery for gastric carcinoma
}

\author{
H. DAINTREE JOHNSON
}

From London

SYNOPSIS This paper presents practical points concerning palliative surgery for carcinoma of the stomach. The results which may be obtained are evaluated.

Surgery for carcinoma of the stomach as we know it in Great Britain carries a high operative mortality and a low proportion of lasting cures. Most of the operations are therefore doomed to be no better than palliative. However, the likelihood that symptoms will be alleviated is very good, and palliation may reasonably be hoped to last for a year or two even though the patients are mostly elderly.

A palliative operation lengthens the lives of some and shortens those of others, but it relieves the vomiting in most and is without question potentially the most humane treatment. To deserve this description, however, it must avoid the implication that those who succumb shall have to suffer pointlessly in the interval between operation and death, intubated, splinted, dripped, and miserably uncomfortable. It is the doctor who has watched the sometimes disastrous sequelae of ill-planned, illmanaged, would-be surgical palliation who is apt to say, 'I would rather my patients died of their diseases than of their treatments'. The management described here avoids this threat.

A distant metastasis which is easily removable does not contraindicate palliative surgery. Indeed, the pathology is not always what it has been taken to be. A huge gastric ulcer in a patient of 77 was thought to be neoplastic, partly because there was a hard nodule at the umbilicus, but this turned out to be a sebaceous cyst. Another old lady who had a palliative total gastrectomy for a leather bottle stomach also had a mass of carcinomatous glands resected from the left axilla. These were found to contain spheroidal-celled growth, and a microscopic second primary was found in the breast at post-mortem examination after 14 months of excellent palliation.

\section{PREPARATION FOR OPERATION}

The preparation of patients thought probably to have incurable disease is not always meticulous. But, as bronchopneumonia is the commonest cause of post-operative death in these patients, oral preparation and dental preparation are particularly important and should not be omitted.

It is astonishing how often patients with neoplasms of the stomach, in spite of having spent a week or two in hospital, are found at operation to have stomachs packed with the shucks of haricot or broad beans and other coarse, undigested vegetable remains which must have made the accommodation and digestion of solid food impossible. A week of high-protein fluid feeding, sometimes preceded by a stomach wash, is therefore now used.

It is quite common for a patient with a carcinoma of the stomach to need resection of a piece of attached colon. All patients are therefore prepared for large-bowel surgery with a sulphonamide and neomycin. If the stomach is achlorhydric it is likely to be teeming with organisms, and this population as well as that in the colon is reduced by these drugs.

\section{THE INCISION}

Carcinomatous patients heal badly and are extra prone to infection and disruption of the wound, as well as to the peritonitis, ileus, and distension which often precede it. This has to be borne in mind when choosing the approach and its subsequent closure.

If there is any question that the proximal half of the stomach may be involved, a thoraco-abdominal exposure is used to allow of a more thorough and careful removal of involved tissue. Even for antral lesions this approach also allows a much more satisfactory dissection of the lymph nodes around the aorta, coeliac axis, and pancreas. The patient is put in the right lateral position and laparotomy is performed through a small left oblique abdominal incision, operability being assessed before the cut is continued into the chest.

\section{THE LAPAROTOMY}

If there is any hope of cure a standard radical operation is carried out, with either total, partial 
proximal, or partial distal gastric resection as indicated by the age and fitness of the patient and the extent and position of the lesion.

If resection for cure is impracticable, the feasibility of palliative operation is considered. Short-circuiting operations - gastro-enterostomy, oesophagojejunostomy, antral exclusion-have carried very high mortalities and morbidities and have been all too often disappointing in their results, though they are better than nothing when gastrectomy is out of the question. Gastric resection is far the most successful palliative operation where it is possible but it must not be thought that palliative gastrectomy is just a would-be-curative gastrectomy which has failed. When it is deliberately undertaken it is a different operation with different principles, though some of the details of management described may be adopted for all resections for gastric cancer with advantage. There is often some uncertainty whether resection is feasible and trial dissection may be necessary before any irrevocable step, such as division of the duodenum, is taken.

In borderline cases, if no symptoms urgently calling for palliation, such as vomiting or dysphagia, are as yet present, care is taken not to go too far before having to abandon the attempt to free the growth from vital structures. On the other hand, when unrelievable symptoms are so severe that failure to survive operation could only be counted a merciful release, a more determined effort is felt to be justified. In one such patient separation of an attachment left a gushing tear in the coeliac axis and aorta. The tear was repaired, however, and the the patient is still living, relieved of his pain and vomiting and doing his job.

Palliative resection is not considered justifiable if there are peritoneal seedlets and free fluid, or if carcinoma is invading the aorta, the coeliac or hepatic arteries, the superior mesenteric vessels, portal vein, or liver. However, intrahepatic metastases are not accepted to be a bar to palliative resection unless large or numerous, and involvement of spleen, pancreas, mesocolon, middle colic vessels, colon, diaphragm, or abdominal wall, are not held to preclude resection.

\section{PALLIATIVE RESECTION}

The principles of palliative resection are that it shall be as fully radical as required by the extent of the main growth but include no inessential prophylactic resection of uninvolved tissue. Glands are removed as may prove convenient, but even involved glands may be left if adherent to vital structures and separate from the main growth. They should not be cut across and dissection between them and the main mass has to be meticulous. There is no need to remove uninvolved omentum and the operation may be begun, as for benign ulcer, by opening through the great omentum into the lesser peritoneal sac. The mesocolon is often involved in growth and a patch of it may sometimes be cut away without difficulty. If the middle colic vessels are involved the mesocolon is opened and their origin identified. If this and the superior mesenteric vessels are clear the middle colic vessels are ligated, and the involved parts stripped up with the main mass and a piece of mesocolon. Pulsating colonic arteries are then sought on either side of the mass and the intervening segment of devascularized colon isolated between Ogilvie clamps, resected, and left attached to the stomach. Similar steps are taken if the colon itself is involved.

If there is any healthy stomach wall well clear of growth it is saved, and in this case an adequate blood supply to it must be assured by keeping intact either the trunk of the left gastric artery and its ascending branch or the splenic artery and some of its short gastric branches. It is my belief that the arteries of the oesophagus alone cannot be relied upon to nourish more than a tiny fringe of stomach in an elderly carcinomatous patient. If both splenic and left gastric arteries have to be sacrificed it is safer not to conserve more than the first threequarters of an inch of stomach, though this much is kept if possible for the sake of its peritoneal covering. Sometimes, though the pancreas is involved, the splenic vessels may be dissected off it and saved for the sake of their short gastric branches. Several short pancreatic venous tributaries require ligation as well as one or two arterial branches.

An adherent body or tail of pancreas may be divided from its neck with ease after ligation or separation of the splenic vessels. If the splenic vessels are divided care is taken to recognize and, if possible, preserve the inferior mesenteric vein, though its retention is not vital unless transverse colon has been resected. Two oblique scalpel cuts are made, major 'bleeders' are picked up, and the pancreas then oversewn with fine silk with a crossing return stitch (Fig. 1).

If the neck and head of the pancreas are involved, an attempt is made to separate them from the underlying portal vein. If this proves practicable the operation is continued. As much pancreas as possible is preserved, but astonishingly little will maintain life. (This was shown by one of my patients who survived 11 months with a piece of pancreas no bigger than a shilling, then died suddenly in the street from haemorrhage from an intrahepatic haemangioma.) The hepatic artery is identified and uncovered before, and kept in view during, dissection 


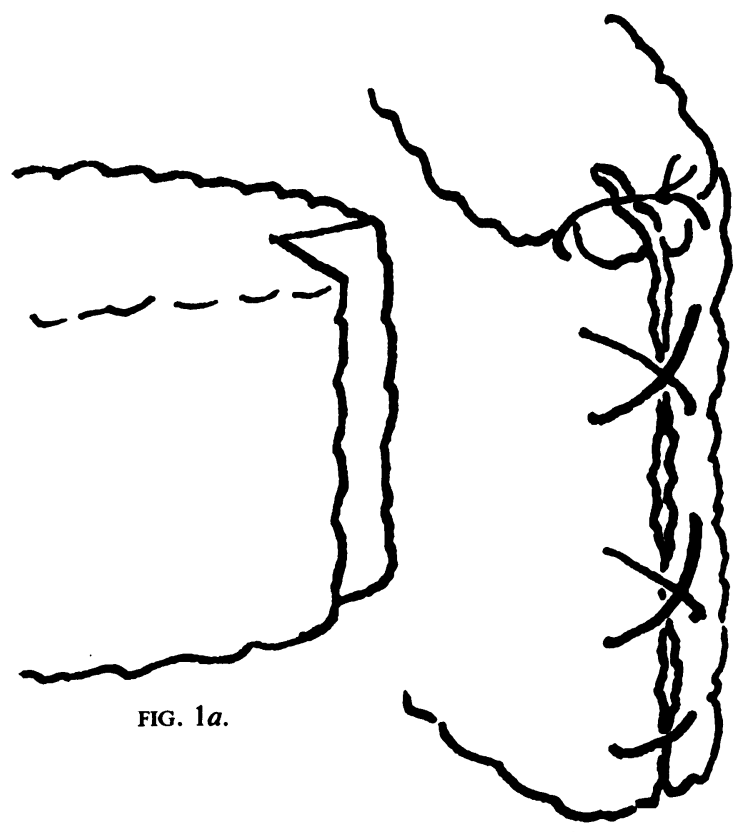

FIG. $1 b$.

of the lesser curve lest it be inadvertently ligated. The gastroduodenal artery is not divided if this can be avoided.

It is considered particularly important that the anastomosis between stomach and duodenum or jejunum should be absolutely free from tension, as breakdown and leakage are more apt to occur in these subjects. For the same reason I prefer to use the jejunum rather than the duodenum with its unperitonealized friable posterior wall, and the interrupted silk or linen thread sutures of the seromuscular layer always take two bites each (figure-of-eight) and are not tied tightly.

When a substantial resection has included splenectomy an empty space appears below the left diaphragm which fills with small bowel. A rare complication which sometimes supervenes is volvulus of the bowel newly occupying this region, and most surgeons meet this sooner or later as a cause of death. Coils of jejunum are therefore deliberately arranged in the space to the best advantage possible at the end of the operation.

An important and valuable additional step is the construction of a temporary jejunostomy. This is potentially dangerous and liable to fatal intraperitoneal leakage unless made by a rigid, well-tested technique and with great care.

Two ordinary gastric suction tubes (or Jaques oesophageal tubes) are used and are introduced into the jejunum through openings, the first 3 or 4 in. below the gastro-jejunal anastomosis or the duodeno- jejunal flexure, and the other $2 \frac{1}{2}$ in. further down. The first tube, which should have large suction noles along 6 or 7 in. of its terminal length, is led back through the anastomosis, its tip being transfixed by a fine silk or thread suture and sewn to the greater curve of the stomach, taking a small bite. This stitch is loosely tied and buried by another which is figure-of-eight and picks up only the seromuscular coat. The second tube, which may be narrow, is passed 3 or 4 in. down the jejunum away from the anastomosis and is used for feeding. Both tubes are buried snugly in the wall of the jejunum Witzel-fashion, by a continuous fine silk suture, so that they emerge together. The tubes and the ends of both continuous silk sutures are passed through a single hole in a leaf of omentum and the sutures used to fasten the jejunum securely to the peritoneal edges of a small stab wound well separated from the main incision. The feeding tube is marked with a ligature outside the abdomen (Fig. 2).

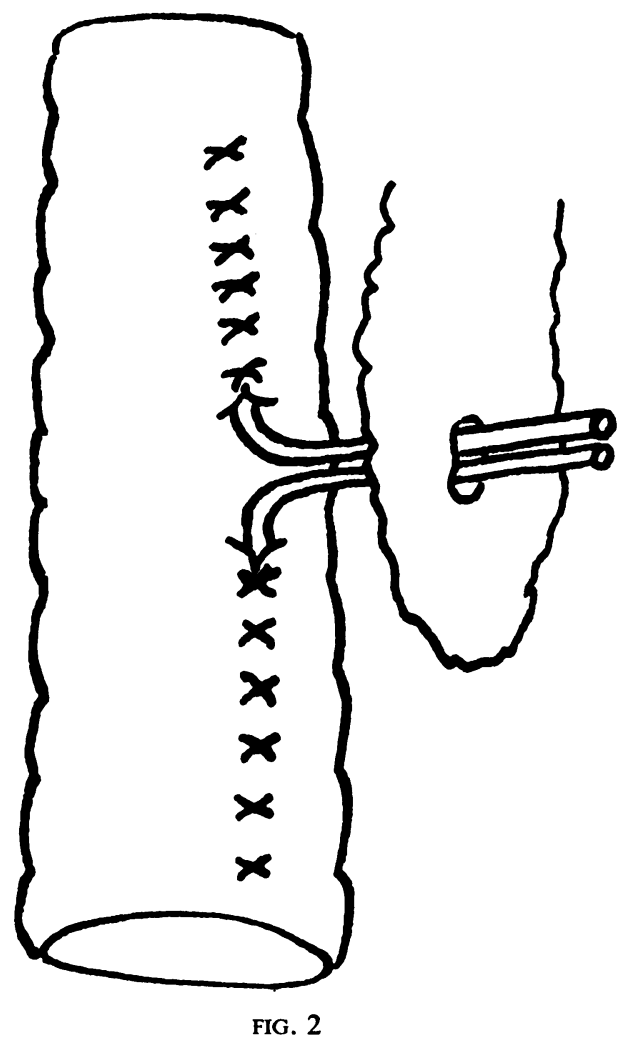

Finally, a soft plastic drain, not a piece of hard corrugated rubber, is introduced down to the anastomosis and the stump of the pancreas if this has been partially resected. This drain is brought out through a separate stab wound in the flank. 
Jejunostomy as an additional step in the technique of gastrectomy for cancer simplifies the postoperative management and is invaluable in the not infrequent cases of prolonged ileus or of leakage at the anastomosis. By dispensing with a nasal tube and often making possible the early discontinuation of intravenous infusion, it also ensures that those who do not recover after the operation shall suffer less discomfort during their last days.

The gastric tube is kept continuously sucked by a pump, at not more than $2 \mathrm{lb}$. to the square inch negative pressure, for the first three days or longer. If the patient's general condition is good he is allowed small frequent drinks of water from the second or third day provided they are seen to be immediately sucked out into the bottle of the continuous suction apparatus. Jejunal feeds are given freely when bowel sounds are present, but a cautious water or half-saline, half-milk drip may begin earlier if hourly aspirations of both tubes are performed. Unless jejunal feeds are small they are apt to cause colic and drip feeds are often tolerated best. If the discharge from the drain is copious and suggests leakage from the anastomosis, a methylene blue tablet is given by mouth which stains it immediately if a leak is present. If a leak occurs, oral feeds are stopped and continuous suction reestablished until the leak heals. Jejunal feeds are continued, however, provided a methylene blue tablet in the jejunal feed does not stain the discharge.

\section{PROXIMAL GASTRECTOMY}

For a growth involving the cardia which is obstructing swallowing a thoraco-abdominal approach is always used. It is usually but not always necessary to divide the diaphragm but there should be no hesitation in resecting any small piece involved in the growth. If the lesion is too advanced for radical would-be curative resection, but a palliative resection is feasible, total gastrectomy is sometimes unnecessary and the distal part of the stomach may be conserved. The left gastric artery is divided at its origin and the spleen and most of the pancreas are resected. However, the blood supply to the gastric stump is adequate if the right gastric and the right gastro-epiploic arteries are left intact. The right gastric artery alone is not always enough and the epoploic arcade is deliberately and carefully preserved up to the level of resection.

Before the oesophago-gastric anastomosis is completed a gastric tube is passed just through the anastomosis into the oesophagus. The tube is tethered to the gastric wall by a silk stitch near the anastomosis and this stitch buried by another. The open end of the tube is then threaded onto a short curved length of metal rod or a gum elastic bougie to serve as a bodkin and guided down the duodenum and into the jejunum, where it is later delivered and used for suction as previously described.

After oesophago-gastric anastomosis a pyloroplasty is necessary as the vagi have been inevitably destroyed. My practice is to divide serosa and muscle only, in the line of the bowel, as in Ramstedt's pyloro-myotomy, and then sew up these coats transversely, as in the Mikulicz operation, with a single continuous suture.

If not even a palliative resection is possible an oesophageal dilator may be passed, and guided through the growth from within the abdomen. A plastic Mouseau-Barbin tube is then attached to its upper end and pulled into position in the stricture after the dilator has been delivered through a small opening in the stomach wall, or even the duodenal wall, distal to the growth. This technique may also be attempted in a case of non-resectable, leatherbottle stomach, instead of oesophago-jejunostomy with its high rate of failure.

\section{AFTER-CARE}

Survivors from very radical gastrectomies have difficulty in maintaining body weight and require very frequent small feeds. These should be mainly of protein and, unless bilous regurgitation is troublesome, should contain plenty of fat. Fruit and green vegetables should be almost completely avoided and extra vitamins will be required. Of minerals, probably only iron will need to be subsidized but two or three tablets daily of ferrous sulphate co. or its equivalent should be given. If the patient survives for more than a year or so regular injections of vitamin $B_{12}$ may become necessary and a regular review of the blood picture is the rule.

Drinking with meals should be minimal, but water and fruit juice should be taken between meals, as well as milk drinks provided they do not precipitate the 'dumping' syndrome.

If much pancreas has been resected, steatorrhoea may be troublesome and pancreatin should be given as well as kaolin or chalk; the fat intake should be reduced. Insulin is not usually required even when only a tiny piece of pancreas has been left.

\section{RESULTS}

Over the years I have tended to undertake gastrectomy more and more often with the object of palliating or forestalling distressing symptoms, even in cases in which there was virtually no hope of cure. In this series, up to five years ago resection was performed in $59 \%$ of those who had undergone 
laparotomy, but during the last five years this figure has risen to $77 \%$. Nevertheless the overall operative mortality for patients who were explored surgically has been reduced from $49 \%$ to $28 \%$ over the same period, and the mortality for gastric resection has fallen from $25 \%$ to $19 \%$. In the whole series over a half of those who died were over 70 years of age and an exactly similar number of septuagenarians survived resection.

At laparotomy patients were deemed beyond cure if the growth or the glands were adherent to an adjacent organ, or if there was an irremovable metastasis. Mortality for resection among such cases was $27 \%$. Subsequent examination of surgical specimens has shown that even of the others very few in this series came to operation at a stage which offered reasonable hope of cure. Indeed, in all but three instances the serosal coat of the stomach had been breached by carcinoma, and lymph nodes were already involved. In those patients, thought at laparotomy to be worthy of an attempt at cure, resection cost the lives of $16 \%$ and, during the past five years of $8 \%$.

Total resection had not been used unless the patient was relatively young and strong, or unless the extent of the lesion compelled it. The few undergoing total gastrectomy have therefore included a number with desperate and advanced lesions and half of them succumbed. The death rate for partial resections was $13 \%$. Carcinoma of the cardia, often reported to carry the worst prognosis, has carried the best in this series. This may be partly due to the fact that, in the presence of dysphagia, operation has most often not awaited positive radiological findings. Another reason is that all have been operated upon by a thoraco-abdominal approach which gives a particularly good opportunity for clearing aerolar tissue and glands around the aorta, coeliac axis, and pancreas.

The five-year survival figures have been disappointing; but it must be borne in mind that the majority of the patients were elderly and their expectation of life was short even had they not had carcinoma. Indeed, the five-year survival figures which have been reported from some centres imply that the patients must have been a great deal younger than those commonly seen with carcinoma of the stomach in Great Britain. The results also reflect the advanced stage at which the patients have come to surgery.

Though patent medicine advertisements have led many of my patients to waste time trying a great variety of antacids before going to their doctors, it is regrettable that for many of them there has been further delay, sometimes too long, before they were referred to hospital for investigation. Even then some patients have wasted more valuable weeks because of the all-too-frequent attitude of 'a week

TABLE II

ALL RESECTIONS

\begin{tabular}{cccc}
$\begin{array}{l}\boldsymbol{x} \\
\text { Years }\end{array}$ & $\begin{array}{l}\text { No. of All } \\
\text { Operations } x \\
\text { or More } \\
\text { Years Ago }\end{array}$ & $\begin{array}{l}\text { No. of Gastric } \\
\text { Resections } x \\
\text { or More } \\
\text { Years Ago }\end{array}$ & $\begin{array}{l}\text { No. of } \\
\text { Surviving } \\
\text { Resectio } \\
\text { or More } \\
\text { Years }\end{array}$ \\
\hline$\frac{1}{2}$ & 103 & & \\
1 & 95 & 72 & 57 \\
$1 \frac{1}{2}$ & 88 & 66 & 52 \\
2 & 79 & 59 & 45 \\
3 & 63 & 52 & 41 \\
4 & 50 & 41 & 32 \\
5 & 41 & 30 & 24 \\
& & 24 & 18
\end{tabular}

No. of Patients
Surviving $x$
or More
Years after
Resection
Percentage of Surgical Patients Alive $x$ or More Years after Operation

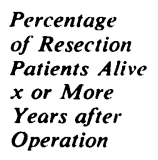

81


TABLE III

\begin{tabular}{|c|c|c|c|c|c|c|}
\hline & $x$ Years & $\begin{array}{l}\text { No. of Gastric } \\
\text { Resections } x \text { or } \\
\text { More Years } \\
\text { Ago }\end{array}$ & $\begin{array}{l}\text { No. of Patients } \\
\text { Surviving } \\
\text { Operation }\end{array}$ & $\begin{array}{l}\text { No. of Patients } \\
\text { Alive } x \text { Years or } \\
\text { More after } \\
\text { Operation }\end{array}$ & $\begin{array}{l}\text { Percentage of } \\
\text { Resection } \\
\text { Patients }\end{array}$ & $\begin{array}{l}\text { Percentage of } \\
\text { Resection Survivors }\end{array}$ \\
\hline $\begin{array}{l}\text { Palliative } \\
\text { Resections }\end{array}$ & $\begin{array}{l}\frac{1}{2} \\
1 \\
1 \frac{1}{2} \\
2 \\
3 \\
4 \\
5\end{array}$ & $\begin{array}{r}29 \\
26 \\
23 \\
19 \\
12 \\
7 \\
5\end{array}$ & $\begin{array}{r}21 \\
19 \\
16 \\
14 \\
9 \\
6 \\
4\end{array}$ & $\begin{array}{r}15 \\
12 \\
3 \\
2 \\
0 \\
0 \\
0\end{array}$ & $\begin{array}{r}52 \\
47 \\
13 \\
11 \\
0 \\
0 \\
0\end{array}$ & $\begin{array}{r}71 \\
63 \\
19 \\
14 \\
0 \\
0 \\
0\end{array}$ \\
\hline $\begin{array}{l}\text { Curative } \\
\text { Resections }\end{array}$ & $\begin{array}{l}1^{\frac{1}{2}} \\
1 \frac{1}{2} \\
2 \\
3 \\
4 \\
5\end{array}$ & $\begin{array}{l}43 \\
40 \\
36 \\
33 \\
29 \\
23 \\
19\end{array}$ & $\begin{array}{l}36 \\
33 \\
29 \\
27 \\
23 \\
18 \\
14\end{array}$ & $\begin{array}{r}31 \\
25 \\
19 \\
11 \\
7 \\
4 \\
2\end{array}$ & $\begin{array}{l}72 \\
62 \\
53 \\
33 \\
24 \\
17 \\
11\end{array}$ & $\begin{array}{l}86 \\
76 \\
66 \\
41 \\
30 \\
22 \\
14\end{array}$ \\
\hline
\end{tabular}

or two more will not make any difference', and some patients have lost still more time because the results of their earliest investigations were negative. Among the latest 50 patients, seven had negative radiographs at the time of their first hospital consultation, and of eight cases of carcinoma of the cardia, there were negative radiographs in three, even at the time of operation. In one case a patient had undergone radiographic examination and oesophagoscopy for dysphagia at another hospital, with negative results, three months before being referred on account of persistent symptoms and weight loss; in another negative radiography and oesophagoscopy, followed by failure to get a view through a gastroscope, led to a delay of three months before laparotomy was decided upon. In a third patient gall-stones were seen in an otherwise normal barium meal radiograph. The patient was referred for thesc and at operation was found also to have a carcinoma at the cardia.
LONG-TERM RESULTS

In reading cure rates it is important to note whether these have been expressed as percentages of resections performed, of would-be-curative resections, or of survivors from resection. The proportion of patients undergoing resection also has a bearing on the results. In this series, of all the patients who underwent laparotomy (with or without resection) $44 \%$ were alive six months later; of those who were able to have resections $64 \%$, and of those who survived resection, $81 \%$. After two years the figures were 16, 25 , and $32 \%$. A patient who underwent a palliative gastrectomy had only a $50 \%$ chance of surviving operation and a subsequent period of life of six to 12 months, but of those who were readmitted after recurrence none was vomiting, unable to swallow, or in uncontrollable pain, and all died in coma. Twenty-two of the patients are alive at the present time, and this includes all of the only three

TABLE IV

\begin{tabular}{|c|c|c|c|c|c|c|}
\hline & $x$ Years & $\begin{array}{l}\text { No. of Gastric } \\
\text { Resections Done } \\
x \text { or More } \\
\text { Years Ago }\end{array}$ & $\begin{array}{l}\text { No. of Patients } \\
\text { Surviving } \\
\text { Operation }\end{array}$ & $\begin{array}{l}\text { No. of Patients } \\
\text { Alive } x \text { Years } \\
\text { or More after } \\
\text { Operation }\end{array}$ & $\begin{array}{l}\text { Percentage of } \\
\text { Resection Patients } \\
\text { Alive at } x \\
\text { Years }\end{array}$ & $\begin{array}{l}\text { Percentage of } \\
\text { Resection Survivors } \\
\text { Alive at } x \\
\text { Years }\end{array}$ \\
\hline $\begin{array}{l}\text { Resections (all } \\
\text { kinds) done over } \\
\text { four years ago }\end{array}$ & $\begin{array}{l}1^{\frac{1}{2}} \\
1 \frac{1}{2} \\
2 \\
3 \\
4 \\
5\end{array}$ & $\begin{array}{l}30 \\
30 \\
30 \\
30 \\
30 \\
30 \\
24\end{array}$ & $\begin{array}{l}24 \\
24 \\
24 \\
24 \\
24 \\
24 \\
18\end{array}$ & $\begin{array}{r}17 \\
12 \\
9 \\
7 \\
5 \\
4 \\
2\end{array}$ & $\begin{array}{r}53 \\
40 \\
33 \\
23 \\
17 \\
13 \\
8\end{array}$ & $\begin{array}{l}71 \\
50 \\
38 \\
29 \\
21 \\
16 \\
11\end{array}$ \\
\hline $\begin{array}{l}\text { Resections (all } \\
\text { kinds) done less } \\
\text { than four years } \\
\text { and more than six } \\
\text { months ago }\end{array}$ & $\left\{\begin{array}{l}1^{\frac{1}{2}} \\
1 \frac{1}{2} \\
2 \\
3\end{array}\right.$ & $\begin{array}{l}42 \\
36 \\
29 \\
22 \\
11\end{array}$ & $\begin{array}{r}33 \\
28 \\
21 \\
17 \\
8\end{array}$ & $\begin{array}{r}29 \\
23 \\
12 \\
6 \\
2\end{array}$ & $\begin{array}{l}69 \\
64 \\
41 \\
21 \\
18\end{array}$ & $\begin{array}{l}88 \\
82 \\
57 \\
27 \\
25\end{array}$ \\
\hline
\end{tabular}


patients whose lesions had not penetrated all coats of the gastric wall or reached lymph nodes.

The results have also been analysed separately for patients operated upon in recent years and those operated upon earlier (Table IV).

In spite of the policy of more frequent use of palliative resection, results are seen to have improved slightly, even from the point of view of long-term survival. Whether this is due to chance or experience it is impossible to say, for one or two extra survivals can make so much difference to percentage figures in a small series. The results for the earlier period cannot now improve, for all the patients are either dead or have already qualified as five-year survivals. In the later group, however, many are still living and the figures are accordingly improving all the time. There are therefore good grounds for hoping that these will ultimately achieve a more gratifying proportion of lasting cures.

\section{SUMMARY}

For carcinoma of the stomach which is beyond hope of cure palliative resection is the best treatment if it is feasible. The indications and contraindications are given. The operation has different principles from those of would-be-curative resection and calls for different techniques. However, some of these may be applied with advantage to all gastrectomies for cancer. They are described, and the principles of management and after-care are summarized. The results, both immediate and late, are given, and compared with those for operations hoped at the time to be curative. 